\title{
EL PROCESO DE SECULARIZACIÓN Apuntes sobre el cambio histórico de la religión a la ciencia
}

\author{
JOSÉ A. SANTIAGO GARCÍA
}

Universidad Complutense de Madrid

\section{PALABRAS CLAVE ADICIONALES}

Heterogonía de los fines, Sociología de la religión, Sociología de la ciencia.

\section{ADDITIONAL KEYWORDS}

Heterogony of Purposes, Sociology of Religion, Sociology of Science.

RESUMEN. Este artículo se centra en una de las dimensiones del proceso de secularización: la secularización del conocimiento. En primer lugar, el artículo muestra las teorías clásicas de E. Durkheim y M. Weber sobre este proceso. En segundo lugar, se destacan algunas de las más importantes explicaciones que señalan la continuidad entre el saber sagrado y el saber secular. Por último, se propone una interpretación del proceso de secularización del conocimiento por medio del principio de la "heterogonía de los fines".

SUMMARY. This paper focuses on one among the various dimensions of the process of secularization, namely, the secularization of knowledge. Firstly, the paper explores Durkheim's and Weber's classic theories of the secularization of knowledge. Secondly, it discusses some of the most common explanations of this process that point out a continuity between sacred and secular knowledge, respectively. Finally, it proposes an interpretation of the process of secularization of knowledge in terms of the principle of "heterogony of purposes".

Revista Internacional de Sociología (RIS)

Tercera Época, $n^{\circ} 31$, Enero-Abril, 2002, pp. 59-79. 
RIS

REVISTA INTERNACIONAL DE SOCIOLOGÍA

No 31, Enero - Abril, 2002

JOSE A. SANTIAGO GARCÍA

\section{INTRODUCCIÓN}

El debate sobre el carácter secularizado de las sociedades modernas viene determinado por la falta de consenso a la hora de determinar qué es lo que define la secularización. Donde unos autores ven sociedades atrapadas en la "jaula de hierro" de la racionalidad instrumental, otros hablan de nuevas formas de sacralidad y religión, etiquetando a esta última con toda una serie de adjetivos: invisible, implícita, difusa, narcisista, civil, política, etc. La cuestión que hay que dilucidar es si estas nuevas formas de sacralidad y religión ponen en entredicho el proceso de secularización o, por el contrario, no son más que la muestra de la confirmación de su triunfo. En efecto, el surgimiento de nuevas fuerzas religiosas en la modernidad avanzada no necesariamente debe ser conceptualizado en términos de desecularización. Esta aparente contradicción queda aclarada cuando se da cuenta de los distintos planos de significación a los que hace referencia el término secularización, un término muy cargado de significados debido a su diversa utilización en diferentes campos del saber, como la filosofia, la teología o las diferentes ciencias sociales. Incluso en disciplinas concretas, como la sociología de la religión, se constata el carácter multidimensional de este término, pues con él se hace referencia a diferentes procesos que, a pesar de su conexión, deben ser distinguidos analíticamente. A este respecto, K. Dobbelaere $(1981 ; 1999)$ es uno de los teóricos que más ha contribuido a delimitar lo que se debe entender por secularización. Este autor distingue tres niveles donde ésta puede acontecer: en los niveles macro, meso y micro, o, dicho de otro modo, en los niveles del sistema social, organizacional e individual. Si seguimos, por tanto, a este autor, la secularización puede tener lugar en tres dimensiones de la vida social que son relativamente independientes. Así, se podría interpretar la secularización como proceso de laicización, de cambio religioso o de declinar de la participación religiosa, en función, respectivamente, de que ese proceso tuviese lugar en el nivel del sistema social, en el organizacional o en el individual (Dobbelaere, 1981). Esta distinción analítica es de enorme valor, ya que permite romper con la unilateralidad que suponen las teorías que hablan de la tesis de la secularización como un proceso creciente, global y unidireccional, y al mismo tiempo poner en entredicho las tesis que hablan de desecularización tout court. $\mathrm{Al}$ distinguir los tres niveles señalados, podemos entender las polémicas habidas en torno al debate sobre la secularización y ver la complejidad que este proceso encierra. Sociedades que en el nivel del sistema social deben ser definidas como seculares, pueden ser al mismo tiempo sociedades con altos porcentajes de participación religiosa en el terreno institucional. En la misma línea, se puede señalar que el surgimiento de nuevos movimientos religiosos puede no ser más que la respuesta ante sociedades ampliamente secularizadas que, sin embargo, no ven peligrar su carácter secular, ya que el ámbito de influencia de aquéllos no es el sistema social. 
Distinguiendo analíticamente estos tres niveles, podemos constatar que donde más firme parece mostrarse la tesis de la secularización es en el nivel del sistema social. La secularización hace en este caso referencia al proceso de diferenciación por el cual la religión dejó de ser el centro sagrado de la sociedad para pasar a situarse como una esfera más al lado de otras. El debate consiguiente se centra en la cuestión de cuál es el lugar que ocupa o debe ocupar la religión en el diferenciado mundo moderno, ya sea en la esfera privada, como sostenían T. Luckmann y N. Luhmann, o en la esfera pública, como sostiene J. Casanova. Pero, al margen de esta polémica, sea en su vertiente descriptiva o normativa, lo cierto es que, como señala el propio J. Casanova: "El núcleo y la tesis centrales de la teoría de la secularización es la conceptualización del proceso de modernización de la sociedad como un proceso de diferenciación y emancipación estructural de las esferas seculares - principalmente el Estado, la economía y la ciencia - respecto a la esfera religiosa y la diferenciación y especialización concomitantes de la religión dentro de su propia esfera recién hallada" (Casanova, 2000: 36).

Los procesos que dieron lugar a esa diferenciación y emancipación estructural de las distintas esferas han sido objeto de estudio por parte de la sociología desde sus inicios. De esas esferas, la que más atención ha despertado ha sido la económica, debido principalmente a la influencia de las tesis weberianas sobre la ética económica de las religiones universales y en especial a su tesis sobre la ética protestante y el espíritu del capitalismo. Junto a la economía, la sociología también ha mostrado un gran interés por el proceso de emancipación de la esfera científica con respecto a la religiosa. ¿Cuándo y dónde se originó este proceso?, ¿qué agentes resultaron decisivos?, ¿en qué términos debemos dar cuenta de dicho proceso? El presente artículo pretende profundizar en esta línea de investigación. En primer lugar, se señalarán las argumentaciones con las que E. Durkheim y M. Weber dieron cuenta del paso de la religión a la ciencia en el marco de sus respectivas teorías sobre la diferenciación. Tras mostrar cómo ambos autores plantearon el paso de la religión a la ciencia, no como un proceso de enfrentamiento y ruptura, sino, todo lo contrario, como un proceso de continuidad entre estas dos esferas del saber, nos adentraremos a ver cuáles fueron los agentes históricos que tuvieron un papel determinante en dicho proceso. Después de mostrar la especificidad de Occidente debido a sus "imágenes religiosas del mundo", se retomarán las tesis de R.K. Merton sobre la relación entre el puritanismo y la ciencia, y las contribuciones de B. Nelson, quien destaca, por el contrario, la importancia que tuvieron las áreas culturales católicas en el surgimiento de la ciencia. Ambas aportaciones son de gran valor para ver el papel que cumplieron las figuras de los mediadores, que hicieron posible la transición de la religión a la ciencia, y poder así entender el proceso de secularización del conocimiento a la luz del principio de heterogonía de los fines o de 
RIS

REVISTA INTERNACIONAL DE SOCIOLOGía

№ 31 , Enero - Abril, 2002

JOSE A. SANTIAGO GARCIA

las consecuencias imprevistas de la acción, siguiendo de esta manera la línea interpretativa que Weber señaló en La ética protestante y el espíritu del capitalismo.

\section{LA SECULARIZACIÓN DEL CONOCIMIENTO EN LA OBRA DE E. DURKHEIM Y M. WEBER}

Sin duda fueron E. Durkheim y M. Weber los que de forma más consistente relacionaron la secularización del conocimiento con el proceso de diferenciación. A pesar de las diferencias que podemos encontrar entre sus teorías de la religión, ambos autores coincidían al dar cuenta de la emancipación de la esfera científica, no como el resultado necesario de un enfrentamiento ni de una ruptura radical entre religión y ciencia, sino, todo lo contrario, como el resultado de un proceso de continuidad entre ambas esferas.

Según E. Durkheim, la religión ha cumplido el papel de proto-institución, ya que en ella se encuentra el origen del resto de instituciones sociales: "todas las grandes instituciones sociales han nacido de la religión" (Durkheim, 1982: 390). En los orígenes, la religión se extendía por toda la vida social, de tal manera que sociedad y religión eran una y la misma cosa. Pero paulatinamente, y como consecuencia del proceso de diferenciación, las funciones política, económica y científica se hicieron independientes de la religión y se desarrollaron autónomamente. No obstante, y a pesar de que E. Durkheim privilegiaba y anteponía el conocimiento científico a cualquier otra forma de conocimiento de la realidad, lo cierto es que nunca contrapuso la religión a la ciencia, pues entre ambas había, según el sociólogo francés, una clara relación de continuidad: "las categorías fundamentales del pensamiento y, consecuentemente, la ciencia tienen un origen religioso" (ibidem: 390). Sin embargo, resultaba inevitable que la ciencia acabara asumiendo la función cognitiva que antes detentaba la religión: "el pensamiento científico no es más que una forma más perfecta del pensamiento religioso. Parece, pues, natural que el segundo se difumine progresivamente ante el primero, a medida que éste se hace más apto para llevar a cabo esa tarea (...) Salida de la religión, la ciencia tiende a sustituirla en todo lo que concierne a las funciones cognitivas e intelectuales" (ibídem: 399). Frente a M. Weber, para E. Durkheim la emancipación de la esfera científica no suponía ni el declive de la religión ni el enfrentamiento entre ambas: "Con frecuencia se tiene una idea inexacta sobre (el conflicto de la ciencia y la religión). Pero la religión existe [...], es una realidad. ¿Cómo podría la ciencia negar una realidad? Además, en tanto que la religión es acción, en tanto que es un medio para hacer que los hombres vivan, la ciencia no puede sustituirla [...] De las dos funciones que cumplía en un principio la religión hay una, pero sólo una, que cada vez tiende más a emanciparse de ella: se trata de la función especulativa" (ibidem: 
400). E. Durkheim hacía así referencia a un reparto de competencias entre la religión y la ciencia, que pretendía justificar con su propia teoría. Por un lado, afirmaba que la ciencia no puede sustituir a la religión, en tanto que ésta es un medio para vivir en sociedad. Por otro lado, defendía que era a la ciencia a la que le correspondía desempeñar la función cognitiva, debido a su superioridad, que se evidenciaba en que sólo ella era capaz de conocer la verdadera realidad que se escondía tras la religión. Ésta fue la tarea a la que E. Durkheim se dedicó, concluyendo con una teoría que establecía la siguiente igualdad: Religión $=$ Sagrado $=$ Sociedad .

Al igual que E. Durkheim, M. Weber también dio cuenta del proceso de emancipación de las distintas esferas con respecto a la esfera religiosa. En el 'Excurso' de los Ensayos sobre sociología de la religión, M. Weber se dedicó a mostrar cómo las diferentes esferas de la actividad humana, al seguir su propia legalidad interna, se iban progresivamente independizando de la religión y entraban en conflicto con ella. En concreto, $M$. Weber entendía que era la esfera intelectual la que, al desarrollarse siguiendo sus propios principios, entraba más directamente en conflicto con la esfera religiosa. El desarrollo autónomo del conocimiento racional se oponía a la pretensión de que el mundo estuviera ordenado por un sentido ético-religioso: "El conocimiento racional [...] construyó, siguiendo de un modo autónomo e intramundano sus propias leyes, un universo de verdades que no sólo no tenía nada que ver con los postulados sistemáticos de la ética religiosa racional, a saber, que el mundo, como cosmos, satisface las exigencias de 'ésta' o que muestra un determinado 'sentido', sino que más bien tenía que rechazar de principio esta pretensión. El cosmos de la causalidad natural y el pretendido cosmos de la comprensión ética se enfrentaban en una oposición irreconciliable" (Weber, 1987: 557-8). M. Weber coincidía, por tanto, con E. Durkheim al mostrar cómo la religión perdía su función especulativa, que le era arrebatada por la esfera científica. Pero, al contrario que E. Durkheim, M. Weber sostenía que la autonomización de la esfera de la ciencia iba dejando a la esfera religiosa marginada socialmente, sin capacidad para desempeñar ninguna de las funciones que había cumplido históricamente y condenada a la irracionalidad: "Todo avance del racionalismo de la ciencia empírica desplaza progresivamente la religión de lo racional hasta lo irracional, convirtiéndola en el poder suprapersonal, irracional o antirracional por antonomasia" (ibídem: 553). Por tanto, según $M$. Weber, la religión perdía también su tradicional función social - la misma que E. Durkheim le atribuía como una determinación intrínseca- quedando únicamente como un refugio existencial para los 'débiles de espíritu': "A quienes no puedan soportar virilmente este destino de nuestro tiempo - racionalizado, intelectualizado y, sobre todo, desmitificador del mundo- hay que decirles que vuelvan en silencio [...] al ancho y piadoso seno de las viejas Iglesias, que no habrán de ponerles dificultades. Es inevitable que uno y otro tengan que hacer allí el 'sacrificio del intelecto"' (Weber, 1988: 230). 
Pero al igual que en el caso de E. Durkheim, la interpretación de M. Weber escapaba de los planteamientos positivistas que señalaban que el conocimiento científico racional se desarrolló de forma endógena y autónoma, enfrentándose con la religión hasta imponerse sobre ella. Por el contrario, M. Weber afirmaba que el origen de la racionalidad moderna se encontraba precisamente en el "racionalismo religioso", y que era su propio desarrollo el que actuaba como fuerza histórica secularizante. En efecto, aquél señalaba que la religión también se desarrollaba siguiendo su propia legalidad interna determinada por una ética religiosa de la convicción.

Como sabemos, $\mathrm{M}$. Weber se dedicó en profundidad a dar cuenta de las éticas económicas de las religiones universales, es decir, se centró en el estudio de la esfera económica por ser ésta la que más peso tiene en la actividad cotidiana. En La ética protestante y el espiritu del capitalismo dio cuenta del papel que tuvo el ascetismo intramundano en el despegue del capitalismo moderno. Pero esta tesis era de tal calado que dejaba abiertas futuras nuevas líneas de investigación. El propio $\mathrm{M}$. Weber era consciente de ello y en las páginas finales de tan lúcido libro señaló que una de las tareas próximas para la ciencia sería indagar la relación del racionalismo ascético con los "ideales de vida e influencias culturales, y ulteriormente, con el desarrollo del empirismo filosófico y científico, con el progreso técnico y con los valores espirituales de la cultura" (Weber, 1987: 201). Lo que para M. Weber era una recomendación, R.K. Merton lo convirtió en un mandato, y en su tesis doctoral se propuso hacer lo mismo que aquél había hecho con respecto a La ética protestante. Se trataba de ver en este caso cuáles eran los fundamentos religiosos que habían estimulado el desarrollo de la ciencia y la tecnología en la Inglaterra del siglo XVII.

\section{CATOLICISMO Y PROTESTANTISMO EN EL DESPEGUE DE LA CIENCIA EN OCCIDENTE}

Para determinar el papel que las tradiciones religiosas han desempeñado en la emancipación estructural de la ciencia moderna es necesario previamente mostrar cómo esta última surgió específicamente en Occidente como fruto de determinadas "imágenes religiosas del mundo". A este respecto, es un inexcusable referente el estudio ya clásico La gran titulación: ciencia y sociedad en Oriente y Occidente de J. Needham (1977). Este autor defiende la tesis de que el desarrollo de la ciencia moderna sólo fue posible cuando se consolidó el concepto de ley de la naturaleza. Como ha señalado E. Lamo de Espinosa, basándose en la obra de E. Schrödinger y del propio J. Needham, este concepto de orden y ley natural, junto con el de la irrelevancia del sujeto cognoscente, son la base de la ciencia moderna y el resultado de una pseudosecularización del pensamiento teológico (Lamo de Espinosa, 1994: 54-68). Al comparar Occidente 
y Oriente, J. Needham muestra que el concepto de ley de la naturaleza nunca existió en China con la significación que se le atribuyó en Occidente, y que esta ausencia coadyuvó al escaso desarrollo de la ciencia. Rechazando el determinismo, J. Needham también hace referencia a otros factores económicos o lingüísticos, como el lenguaje ideográfico, que fueron inhibidores del desarrollo científico. Pero centrándose en el concepto de ley de la naturaleza, este autor señala que dicho concepto se desarrolló a lo largo de la historia en estrecha relación con determinadas "imágenes religiosas". Así, su ausencia en la tradición china se explica en buena medida por el cosmocentrismo que caracteriza a la religión oriental. En efecto, para los antiguos pensadores taoístas no era concebible un orden cósmico gobernado por las leyes que un Dios supremo hubiese decretado. Por el contrario, el Tao, el orden cósmico de todas las cosas, actuaba como una norma que no había sido dictada por nadie y era inescrutable para el intelecto humano (Needham, 1977: 311). De ahí que el interés de los taoístas por la naturaleza fuera de carácter místico-experimental más que racional-sistemático. Por su parte, el confucianismo, prototipo de religión de afirmación del mundo, tal y como señaló $\mathrm{M}$. Weber, no contemplaba que el mundo se rigiese por ninguna ley ni sentido ético. Como aquél nos dejó escrito, para el "racionalismo confuciano [...] que rechaza una teodicea intramundana puramente racional [...] lo ultraterreno preocupaba tan poco al hombre distinguido como al común" (Weber, 1987: 403). Por ello, el confucionismo no desarrolló una ética religiosa ni una metafísica racional que derivase en una unidad sistemática en la relación de Dios con el mundo. Acorde con su carácter de religión impulsada por el funcionariado, ésta no alentaba la búsqueda de un sentido ético en el mundo, sino la consecución de una moralidad intramundana de personas laicas que se basaba en la adaptación al mundo, a su orden y convicciones. Era una religión que centraba su interés en el orden social y que no sentía gran curiosidad por los fenómenos de la naturaleza. J. Needham (1977: 325) señala que la "imagen religiosa del mundo" en China se caracterizaba por tres aspectos: a) el ser espiritual al que se adoraba no era un Creador en el sentido de los griegos y los hebreos; b) la idea de un Dios supremo no incluyó la concepción de un legislador divino que impusiera sus órdenes a la naturaleza no humana; y c) el concepto de suprema deidad se despersonalizó muy pronto. No se trata, concluye J. Needham, de que "para los chinos no hubiera orden en la naturaleza, sino más bien de que no era un orden impuesto por un ser personal racional, y por lo tanto no había garantía de que otros seres personales racionales pudieran propagar en sus propios lenguajes terrestres el preexistente código de leyes divinas que aquél había formulado previamente" (ibídem: 325). No había leyes de la naturaleza simplemente porque nadie las había creado: "No se confiaba en que el código de la naturaleza pudiera ser desvelado y leído, porque no había seguridad de que un ser divino, aún más racional que nosotros, hubiera formulado jamás un código que se pudiese leer" (ibídem: 325). El mundo era 
RIS

REVISTA INTERNACIONAL DE SOCIOLOGII

№ 31 , Enero - Abril, 2002

JOSE A. SANTIAGO GARCÍA

concebido como un todo armónico, sin que hubiera autoridad alguna superior a la que hubiese que obedecer.

Por el contrario, según nos dice J. Needham, la idea de leyes de la naturaleza forma parte de la tradición occidental desde hace siglos, aunque dicho concepto sólo alcanzó un estatuto importante en el siglo XVI y no se desarrolló por completo hasta la aparición de los primeros cultivadores del método científico en el siglo XVII ${ }^{1}$. En el siglo XVIII será uno de los conceptos claves que definan la época ${ }^{2}$. Se entiende así el sentido de la afirmación que señala que mientras los pensadores chinos se inclinan a buscar un sentido (Tao), los científicos occidentales buscan una ley (Schrödinger, 1975: 75). Como muestra el caso de China, el desarrollo del concepto de ley de la naturaleza, base de la ciencia moderna, estuvo condicionado por una determinada imagen religiosa del mundo: "las ideas vigentes acerca de un ser supremo, aunque estaban presentes desde los tiempos primitivos, se despersonalizaron [...] impidieron el desarrollo de leyes abstractas impuestas desde los comienzos por un legislador celeste" (Needham, 1977: 325). Como conclusión, se puede señalar que el concepto de leyes de la naturaleza sólo apareció allí donde existía la idea de un Dios ético, personal y supramundano. Y, como sabemos a partir de las tipologías weberianas, fueron los profetas emisarios del Cercano Oriente los que difundieron el mensaje de un

\footnotetext{
${ }^{1}$ J. Needham, siguiendo a E. Zilsel, destaca la relación que hay entre el auge del absolutismo monárquico y el desarrollo de dicho concepto. Éste nació con los estoicos en el período de formación de las grandes monarquías que siguieron a la muerte de Alejandro Magno y se desvaneció con el feudalismo medieval, período de difuminación del poder. Más tarde resurgiría en el Renacimiento con la aparición del absolutismo real. Como señala E. Zilsel y recoge J. Needham: "no es una simple casualidad que la idea cartesiana de Dios como legislador del Universo se desarrollara cuarenta años después de la teoría de Jean Bodin sobre la soberanía" (Needham, 1977: 309). Sobre esta relación puede verse también Lamo de Espinosa et al, (1994: 59-60).

${ }^{2}$ Se puede apreciar el desarrollo del proceso de secularización del conocimiento dando cuenta de las palabras claves que marcaron el clima intelectual en diferentes siglos. $\mathrm{Si}$, como mostraba C.Becker (1932), en el siglo XIII esas palabras claves eran Dios, pecado, gracia, salvación o gloria, en el siglo XVIII las palabras que definían el clima intelectual eran razón, naturaleza y leyes de la naturaleza. Todas ellas hacen referencia a las manifestaciones de Dios. Esta divinización de la naturaleza culminará con el movimiento del Deísmo inglés. A este respecto, debe verse E. Gómez Arboleya (1957), y la recuperación que de esta obra ha hecho E. Lamo de Espinosa (1994: 61). La identificación entre las leyes de la naturaleza y la divinidad resulta definitoria para este movimiento. Así, por ejemplo, W. Wollaston señalaba: "El mundo es gobernado por leyes, leyes por las cuales actúan las causas naturales, se suceden regularmente los varios fenómenos y en general se conserva la constitución de las cosas. Las leyes proceden del autor de la naturaleza. Tales leyes pueden llamarse la divina providencia" (Gómez de Arboleya, 1957: 254). Por su parte, M. Tindal afirmaba que "la religión de la naturaleza se afirma como perfecto cristianismo y por tanto como perfecta religión" (ibídem: 255). En la misma línea, S. Clarke, que estuvo en contacto con el Deísmo, señalaba: "Razón y deidad son lo mismo. Lo que es verdadero por ley de naturaleza o razón de las cosas es, de igual modo, la voluntad de Dios" (ibidem: 257).
} 
Dios al que se le debía obediencia. Por el contrario, la religiosidad del Lejano Oriente se caracterizaba por la falta de profecía o por el triunfo de la profecía ejemplar. Estos profetas ejemplares, que como Buda no predicaban ningún mensaje divino de obediencia, se presentaban simplemente como hombres ejemplares a los que había que seguir si se quería alcanzar la salvación religiosa en un orden cósmico impersonal y supradivino. En la religiosidad oriental falta la profecía emisaria que trae a la tierra el mensaje de un Dios supremo (Weber, 1944: 356-364). Como vemos, la diferente relación de Oriente y de Occidente con la ciencia está condicionada por la distinta "imagen" de la divinidad. En Occidente nos encontramos con un Dios ético, personal y supramundano, que ha decretado leyes para que todos los seres se rijan por ellas. En Oriente, por el contrario, nos encontramos con poderes impersonales supradivinos: "Sin que se tomen medidas se realizan todas las cosas, ese es el Tao del Cielo" (Confucio).

\section{Ad maiorem Dei gloriam. El impulso puritano de la ciencia}

La historia de la ciencia nos demuestra que, en sus orígenes, no se desarrolló en oposición a la religión, sino en perfecta simbiosis con ella. Frente a la tesis positivista que mantenía el mito de la oposición entre ciencia y religión, lo cierto es que ambas coexistieron y colaboraron (Iranzo, 1992: 236-251). La polémica surge a la hora de valorar el estímulo que la ciencia recibió por parte de las diferentes tradiciones religiosas.

La obra de R.K. Merton Ciencia, tecnología y sociedad en la Inglaterra del siglo XVII es sin duda uno de los más importantes estudios sobre la influencia que ha tenido la religión en la ciencia moderna. Según su conocida tesis, el puritanismo fue la tradición religiosa que de forma más clara propició el desarrollo de la ciencia. Siguiendo a M. Weber, R.K. Merton encontró en las "imágenes religioso-metafísicas" del puritanismo la clave para entender el papel que éste desempeñó como factor que favoreció el desarrollo de la ciencia. Al igual que las religiones orientales de carácter místico, el protestantismo defendía la negación del mundo con el que no podía haber reconciliación. Pero, frente a aquéllas, la salvación no se encontraba en la huida del mundo, sino en su dominación. Al mismo tiempo que se negaba el mundo, se veía en su dominación la forma de alcanzar la salvación. Es este doble vínculo - de negación y al mismo tiempo de dominación del mundo- el que nos proporciona la clave para entender por qué el protestantismo coadyuvó al desarrollo de la ciencia.

Para los protestantes el mundo había sido creado por Dios y el hombre debía trabajar en él para aumentar su gloria. Trabajar incesantemente era la forma de aumentar las riquezas mundanas, que no eran sino una manifestación de la divinidad. Al ser el mundo una manifestación de Dios, el estudio de los fenómenos naturales se convertía en un medio de glorificación de su obra. En el 
Christian Directory de R. Baxter encontramos las formulaciones principales del ethos protestante a este respecto 3 : "El gran medio de promover el amor a Dios es contemplarlo debidamente en sus aspiraciones ante el hombre, en los modos de la Naturaleza, la Gracia y la Gloria. Primero pues aprender a comprender y hacer buen uso de sus manifestaciones en la Naturaleza y ver al Creador en todas sus obras, y por el conocimiento y el amor de ellas elevarse al conocimiento y el amor de Él" (Merton, 1984: 101). Los intereses religiosos de la época exigían en sus irrenunciables implicaciones prácticas el estudio sistemático, racional y empírico de la naturaleza, para honrar así a Dios en sus obras y dominar el mundo. Además, y esto es muy significativo, la ciencia contribuía a resolver un problema que derivaba de la teología protestante: la falta de certitudo salutis, que implicaba la teoría de la predestinación. La angustia existencial que ésta generaba era aliviada por medio de una concepción del trabajo que hacía de él una actividad incesante y metódica. Los propios miembros de la Royal Society apreciaron la funcionalidad que la ciencia tenía para el ethos protestante: “¿qué hay, se preguntaba Sprat, más activo, industrioso y sistemático que el Arte del Experimento, que nunca puede llegar a su fin por los trabajos perpetuos de un solo hombre, ni siquiera por las fuerzas sucesivas de la mayor de las asambleas?" (Merton, 1984: 118). La metodización y sistematización de la práctica científica hacían olvidar la incertidumbre de la salvación y las tentaciones mundanas. Y puesto que era Dios quien llamaba al trabajo constante, el éxito en la labor científica, al igual que en la esfera económica, se interpretaba como una señal de la elección divina. La ciencia era por tanto funcional al ethos protestante. Por eso, los estudios más valorados por los puritanos fueron la física y la matemática, que se consideraban como los medios para acceder a Dios a través de sus manifestaciones en la naturaleza.

Pero R.K. Merton no planteó una tesis idealista que hiciera del puritanismo el factor que determinó el desarrollo de la ciencia ${ }^{4}$. Tanta o mayor importancia

\footnotetext{
${ }^{3} \mathrm{Al}$ igual que Max Weber, R.K. Merton encontró en el Christian Directory de Richard Baxter una presentación típica de los principales elementos del ethos puritano.

${ }^{4}$ En el prefacio de la edición de su obra en 1970, R.K Merton recalcaba que había que interpretar su tesis sobre la relación entre el puritanismo y el desarrollo de la ciencia en términos de funcionalidad: "no ocurrió que el puritanismo fuese indispensable, en el sentido de que, si éste no hubiese hallado expresión histórica en ese tiempo, la ciencia moderna no habría surgido. No presentamos el movimiento históricamente concreto del puritanismo como un requisito para el sustancial impulso de la ciencia inglesa por aquel entonces [...] La interpretación que se sustenta en este sentido supone el requisito funcional de brindar un sostén social y culturalmente pautado a una ciencia todavía no institucionalizada, pero no presupone que sólo el puritanismo podría haber cumplido tal función. Ocurrió que el puritanismo brindó un importante apoyo (no exclusivo) en aquel tiempo y lugar históricos. Pero esto no lo hace indispensable" (Merton, 1984: 20).
} 
que los intereses ideales del puritanismo tuvieron los condicionamientos económico-militares que se produjeron en la Inglaterra del siglo XVII. En efecto, las diferentes utilidades prácticas de la ciencia fueron un factor clave para su desarrollo. R.K. Merton volvía sobre ello en el prefacio a la nueva reedición de su obra en 1970, señalando que las críticas que había recibido su libro, que se habían centrado casi exclusivamente en la hipótesis que vinculaba el puritanismo con la ciencia, parecían olvidar esta otra hipótesis acerca de las influencias económicas y militares sobre el ámbito de la investigación científica (Merton, 1984: 14)5.

No obstante, la utilidad social era también un fin prescrito por la religión. El empleo debía ser elegido como medio para ser más útil a Dios, pero también para contribuir al bien común. Se iniciaba así la transición desde la justificación del trabajo científico como forma de glorificar a Dios, a la exaltación del utilitarismo. El criterio utilitario iba desplazando a la glorificación de Dios como motivación y legitimación de la práctica científica. En este proceso de transición desempeñaron un papel crucial las figuras de los mediadores, tal y como veremos más adelante.

\section{El profetismo católico y los orígenes de la ciencia}

El apartado anterior no es más que una simple exposición de la ya clásica tesis de R.K. Merton sobre la importancia que tuvo el protestantismo en la génesis de la ciencia moderna. Pero desde que R.K. Merton escribiera su tesis en 1938

\footnotetext{
${ }^{5} \mathrm{La}$ tesis de R.K. Merton supuso una alternativa a la polarización que tenía lugar en el estudio de la ciencia entre los "internalistas", que defendían que el progreso científico únicamente respondía a contenidos cognitivos y al desarrollo del propio método, y los "externalistas", para quienes el desarrollo de la ciencia debe explicarse a partir del contexto económico y social donde los científicos llevan a cabo su trabajo. R.K. Merton buscaba un equilibrio entre las variantes idealista y materialista del enfoque externalista y establecer una síntesis con respecto a la dicotomía internalismo/externalismo, señalando que, si bien es cierto que el contexto externo orienta el desarrollo de la ciencia hacia unos determinados intereses, esa influencia externa no alcanzaba a los contenidos concretos de la ciencia. Aunque R.K. Merton no pudo conciliar las posturas "internalistas" y "externalistas", su obra tuvo el mérito de significar el inicio de la historia institucional de la ciencia (Iranzo y Blanco, 1999: 66; Lamo de Espinosa et al, 1994: 463). En referencia a la polémica internalismo/externalismo en la historia de la ciencia, E. Medina juzga así la obra de R.K. Merton: "la tesis doctoral de Merton (1970) sobre la ciencia en la Inglaterra del XVII no le permite llegar excesivamente lejos en su análisis, en la medida en que asume el dictum positivista de la autonomía de la racionalidad científica [...] es externalista [...] dedicándose esencialmente a tratar aspectos de las ciencias tales como la 'comunidad científica', la 'estructura social de la Ciencia' o el 'ethos de la comunidad'. Pero son internalistas cuando aceptan que la sociología no tiene nada que decir sobre el contenido del conocimiento científico..." (Medina, 1995: 73).
} 
R IS

REVISTA INTERNACIONAL DE SOCIOLOGÍA

№ 31 , Enero - Abril, 2002

JOSE A. SANTIAGO GARCÍA

se han publicado diferentes trabajos que ponen en tela de juicio algunos de los aspectos de la tesis mertoniana. Se pueden destacar las críticas que hacen referencia a la ambigüedad del término "puritanismo", al momento histórico concreto al que se debe aplicar dicho término o a las precauciones que hay que adoptar al dar cuenta de las verdaderas motivaciones y actitudes de los científicos (Cohen, 1990: 62-75). Algunos autores han criticado la obra de R.K. Merton por el privilegio que concedía al protestantismo como motor de la ciencia y por ignorar la importancia que tuvieron otras tradiciones religiosas como el catolicismo. A este respecto, se pueden destacar las aportaciones de B. Nelson. Este autor reprocha a R.K. Merton que su interés casi exclusivo por el protestantismo le impidiera ver la importancia que en el desarrollo de la ciencia tuvieron las áreas culturales católicas desde el siglo XII hasta el XVII y los desarrollos tecnológicos que se produjeron en la Edad Media (Nelson, 1976) ${ }^{6}$. Lo que pretende la crítica de B. Nelson no es negar la enorme importancia que tuvo el protestantismo en el desarrollo de la ciencia, sino borrar el carácter tan negativo que se le ha atribuido al período medieval y, sobre todo, señalar el papel que realizaron los pensadores católicos al crear las condiciones que permitieron su despegue. En efecto, según B. Nelson, los innovadores de la moderna revolución científica no surgieron de la ética del ascetismo intramundano, sino que se formaron en círculos culturales católicos, como fue el caso de Copérnico, Galileo, Descartes o Pascal. Su gran aportación fue la ruptura que llevaron a cabo con los postulados filosóficos de su época proclamando una nueva verdad, un nuevo paradigma. Esa ruptura, fundamento de la ciencia moderna, fue provocada por aquéllos que como nuevos profetas proclamaron "su convicción de que la certeza objetiva y la intima incertidumbre eran las marcas indispensables de la ciencia, de la verdadera filosofia y de la creencia razonable" (ibidem: 59). Se enfrentaban así al ficcionalismo y al probabilismo

\footnotetext{
${ }^{6}$ A pesar de las discrepancias con R.K. Merton, B. Nelson se opone a las críticas dirigidas a la obra de aquél que niegan que el protestantismo o cualquier otra tradición religiosa haya influido en el desarrollo de la ciencia. En esta línea, tanto R.K. Merton como B. Nelson restan valor a la tesis de L.S. Feuer, que negaba esa influencia apoyándose para ello en la descripción de los miembros de la Royal Society como hedonistas-libertarios. Este autor intentaba mostrar "cómo la ética hedonista-libertaria dio impulso a la revolución científica, y fue realmente el credo de los nacientes movimientos científicos en todas partes" (Nelson, 1976: 57). La réplica de R.K. Merton, que aparece en el prefacio a la citada obra de 1970, se fundamenta en la definición de hedonismo de L.S. Feuer, que ciertamente resulta desmedida: "una vez que el goce en la labor científica se convierte en un signo de hedonismo, no puede haber mucha dificultad para establecer que el muy puritano científico John Ray, o el médico puritano Thomas Sydenham o el piadoso Robert Boyle, eran incorregibles hedonistas" (Merton: 1984: 28).
} 
que defendían los líderes de la instituciones religiosas de su tiempo. El caso de Galileo resulta significativo a este respecto. Con el fin de evitar condenarle, el cardenal Belarmino y el papa Urbano VIII le proponían que diera a sus teorías y a las de Copérnico un estatuto de 'ficciones', es decir, instrumentos de cálculo que no tuvieran pretensión de ofrecer una imagen verdadera de la realidad. Tras su condena en 1633, Galileo sólo estaba autorizado a presentar sus opiniones como ficciones. A pesar de ello, se negó a pactar con el ficcionalismo por considerarlo degradante para un científico como él, que estaba luchando por conocer y proclamar la verdad. $\mathrm{Su} f e$ era una fuente de inspiración que le enseñó a actuar a la luz de su conciencia comprometida y que le llevó a romper con los viejos postulados eclesiásticos (ibídem: 85). Estos "profetas católicos" no eran, por tanto, personajes que pactaban con el poder de las instituciones eclesiásticas, ni hombres escépticos, ni tampoco racionalistas que se oponían a la religión. Por el contrario, creían en la verdad de Dios, pero una verdad que les era revelada por la naturaleza y por los números, y no por las interpretaciones de las Escrituras. Esta ruptura fue la que posibilitó el despegue de la ciencia. B. Nelson se muestra concluyente al señalar el salto cualitativo que provocó el profetismo católico: "El hecho de que el movimiento y la concepción científicos gozaran con el tiempo de una ascendencia mucho mayor entre los protestantes que entre los católicos no debe oscurecer el importante papel que las 'áreas culturales' católicas jugaron en la iniciación de la revolución científica y filosófica de los siglos XVI y XVII. Ni Francis Bacon, ni los miembros de la Royal Society, y ni siquiera Newton, fueron los que pusieron las ruedas en movimiento; fueron Copérnico, Galileo, Descartes, Pascal y otros muchos que habían sido educados en escuelas católicas y que tuvieron que luchar para abrirse camino hacia la convicción de que habían percibido nuevas verdades acerca del libro de la naturaleza" (Nelson, 1976: 76).

\section{EL PRINCIPIO de heterogonía de los fines EN EL PASO DE LA RELIGIÓN A LA CIENCIA}

Hemos visto el soporte religioso desde el que se desarrolló la ciencia. Hoy en día el conocimiento científico no necesita de ninguna legitimidad religiosa. ¿Cómo fue posible este proceso de emancipación y autonomización de la esfera científica con respecto a la esfera religiosa? ¿Cómo podemos dar cuenta de la sustitución del conocimiento sagrado por el secular como conocimiento legitimado socialmente?. La respuesta más consistente la ofrecieron los que vieron continuidad donde otros veían enfrentamiento entre los discursos de la religión y la ciencia. Si anteriormente se han expuesto las tesis de R.K. Merton y de B. Nelson ha sido porque ambos autores, al dar cuenta de la continuidad entre religión y ciencia en las áreas culturales protestantes y en las católicas, 
RIS

REVISTA INTERNACIONAL DE SOCIOLOGIA

№ 31, Enero - Abril, 2002

ofrecieron aportaciones de gran valor para explicar el cambio histórico de la religión a la ciencia a partir del llamado principio de la heterogonía de los fines (Stark, 1971) o de las consecuencias no previstas de la acción.

Tanto B. Nelson como R.K. Merton coinciden al presentarnos a las figuras de los profetas católicos y de los jerarcas protestantes como personajes motivados por valores religiosos irrenunciables que actuaban guiados por una ética de la convicción. Fue el propio R.K. Merton el que en un célebre artículo sobre las consecuencias imprevistas de la acción vio en la defensa de valores básicos una de las posibles fuentes que originaban este tipo de consecuencias (Merton, 1980: 183). Haciendo referencia a La ética protestante y el espiritu del capitalismo, este autor mostraba cómo las consecuencias de la acción no se tienen en cuenta cuando dicha acción está determinada por valores fundamentales. La satisfacción ante el deber cumplido desplaza la preocupación por las consecuencias objetivas de la acción; consecuencias imprevistas que, como señala R.K. Merton, cuando se producen no quedan limitadas al área específica en que tuvo lugar la acción, sino que se extienden por campos relacionados a los que se ignoraba en el momento en que se produjo aquélla. Y como "esos campos están de hecho relacionados, las ulteriores consecuencias en las áreas adyacentes tienden a reaccionar sobre el sistema fundamental de valores" (ibidem: 184). Con esta formulación, R.K. Merton resaltaba que esta reacción constituye un elemento fundamental para entender el proceso de secularización, transformación y desintegración de los valores religiosos, tal y como ya apuntó $\mathrm{M}$. Weber.

En el caso concreto que nos ocupa, la secularización del conocimiento ha de ser explicada a partir de las figuras de los mediadores que hicieron posible esa transformación de los valores con respecto al conocimiento. Para entender este proceso resulta de gran valor analítico la figura del mediador evanescente. Este concepto procede de la obra de F. Jameson, quien ha utilizado el "cuadro semiótico" de A. J. Greimas para dar cuenta de las estructuras narrativas que están presentes en la obra de M. Weber (Jameson, 1974). Siguiendo la interpretación de F. Jameson, R. Ramos profundiza en las determinaciones de esta figura y añade el adjetivo de extraño, para así caracterizarla en términos identitarios (Ramos, 2001: 61). Los agentes históricos a los que así se define son los que, según M. Weber, resultaron cruciales en el proceso de desencantamiento: el profeta y el ascetismo intramundano. Éstos son mediadores extraños porque tienen una identidad formada por dos lógicas sociales que históricamente habían estado separadas y que resultaban incompatibles (ibidem: 61). Gracias a su ambivalencia identitaria consiguen mediar entre esas dos lógicas incompatibles dando así lugar a una nueva configuración histórica. Sin embargo, una vez que estos mediadores cumplen su cometido, su destino es desaparecer, ya que su propia acción da lugar a una nueva realidad que escapa a sus determinaciones y a sus intenciones originarias. En el caso del profeta emisario, éste se nos presenta como un "tipo ideal" caracterizado por estar dotado de carisma personal 
y por anunciar una doctrina de obediencia a Dios. De esta forma, el profeta compatibiliza dos lógicas que históricamente habían estado enfrentadas: el carisma personal propio de la figura del mago y la doctrina propia de los sacerdotes. Por eso, cuando el profeta irrumpe en el campo religioso lo hace como mediador evanescente. Es mediador porque compatibiliza esas dos lógicas enfrentadas que encarnan las figuras de magos y sacerdotes, y hace así posible el paso de la religiosidad mágica y de la religiosidad sacerdotal a una nueva religiosidad ética. $Y$ es evanescente porque fruto de esa mediación da lugar a una nueva religiosidad congregacional que tiene como consecuencia imprevista la rutinización del carisma que le había dado origen. Lo mismo sucede con el ascetismo intramundano en su papel de mediador entre el sentido religioso y la racionalización capitalista. F. Jameson (1974: 71-80) también aplicó en este caso la figura del mediador evanescente para definir al ascetismo intramundano, que hizo posible, gracias a su mediación, el paso de un mundo tradicional cargado de sentido a un mundo moderno racionalizado. La racionalización desacralizó un mundo que pasó a ser extraño a aquéllos que habían contribuido a su racionalización.

Estas figuras de los mediadores evanescentes son igualmente determinantes a la hora de entender el proceso de secularización del conocimiento. A pesar de la disputa sobre la mayor o menor influencia que tuvieron el catolicismo o el protestantismo ascético en el despegue de la ciencia moderna, tanto B. Nelson como R.K. Merton coincidían al señalar el papel fundamental que jugaron las figuras de los mediadores, ya fuese en las áreas católicas o en las protestantes. Para ello, se servían de algunas de las aportaciones más fructíferas que nos ha legado la obra de M. Weber.

La tesis de B. Nelson sobre el papel que cumplieron las áreas católicas en el despegue de la ciencia moderna se construye a partir de la distinción entre los tipos ideales de la religión sacerdotal y la religión profética, que, como hemos visto, es fundamental en la sociología de la religión de M. Weber. Frente a los sacerdotes, que defienden una verdad ya codificada y legitimada institucionalmente, B. Nelson nos habla de "los individuos que insisten en proclamar una poderosa certidumbre (subjetiva) propia o en señalar una certeza (objetiva) que aparece como claramente establecida por una especie de nueva revelación [...] Estos hombres se sienten llamados a actuar como profetas y a hacer manifiesta la verdad de palabra y obra" (Nelson, 1976: 61). Según este autor, Galileo, Descartes, Pascal y otros contemporáneos que vivieron en áreas culturales católicas son expresiones de ese profetismo que se enfrentó a la religión sacerdotal defendiendo una nueva verdad. Fue a ellos a quienes les correspondió esa labor mediadora, a ellos que luchaban contra el ficcionalismo, el probabilismo y el sistema teológico establecido por los jerarcas eclesiásticos. Como señala M.A. Quintanilla, reafirmando la tesis de B. Nelson, los nuevos profetas no simbolizan una ruptura con el pasado, sino una mediación: "La 
nueva ciencia no es una reacción descarnada contra el espíritu religioso, hay que verla más bien en la óptica de las relaciones entre religión institucional y religión profética. Galileo no es un racionalista que se opone a la religión, sino más bien un espíritu profético que se opone a la ideología característica de la clase sacerdotal. En definitiva, pues, la ciencia moderna no fue en sus comienzos ni neutral con respecto a un pensamiento religioso institucionalizado que pretendía definir las pautas para el conocimiento de la realidad, ni independiente de un espíritu religioso en el que necesariamente estaba envuelta" (Quintanilla, 1976: 14).

Esta tesis de B. Nelson nos remite a la sociología de la religión de M. Weber, a las luchas entre los distintos agentes religiosos, a las posiciones que ocupan en el campo religioso y a la capacidad que éstos tienen para imponer una determinada "imagen religiosa" y un habitus a los laicos. Ha sido P. Bourdieu el autor que más ha profundizado en esta línea, criticando y enriqueciendo la teoría de la religión de $\mathrm{M}$. Weber. En palabras de aquél, para resolver las dificultades de la teoría de la religión de $\mathrm{M}$. Weber es necesario llevar a cabo una ruptura fundamental y "subordinar el análisis de la lógica de las interacciones (entre agentes) [...] a la construcción de la estructura de las relaciones objetivas entre las posiciones que ellos ocupan en el campo religioso, estructura que determina la forma que pueden tomar sus interacciones y la representación que pueden tener de ellas" (Bourdieu, 2000: 46). En función de la posición ocupada en la estructura objetiva de un determinado estado del campo religioso los agentes podrán movilizar distintas fuerzas materiales o simbólicas en la lucha por el monopolio del ejercicio legítimo del poder religioso (ibidem: 53). Esta lucha, que M. Weber y P. Bourdieu analizan en el estado del campo religioso en el que se enfrentaban magos, sacerdotes y profetas con el objetivo de imponer un determinado habitus a los laicos, es proyectada por B. Nelson al período en el que los "profetas" de la ciencia se enfrentaban a la jerarquía eclesiástica: "aunque los pioneros de la ciencia y la filosofía modernas hubieran querido adoptar una teoría instrumentalista o falibilista acerca de las leyes científicas, en realidad ya no les quedaba opción, porque las posiciones ficcionalistas y probabilista habían sido ya ocupadas por los jefes del sistema establecido" (Nelson, 1976: 67). En la proyección que hace B. Nelson de la lucha entre profetas y sacerdotes a los orígenes de la ciencia, los laicos juegan un papel más pasivo que activo a la hora de definir la correlación de fuerzas entre aquéllos: "la oposición fundamental a los innovadores no se encontraba en el pueblo supersticioso [...] No podemos forjarnos la idea de que el hombre de la calle se sintió molesto por el talante experimental y falibilista de los científicos. El enemigo no era el hombre sencillo. El verdadero enemigo se encontraba en la élite [...] del establishment eclesiástico, que siguió con gran interés el trabajo de científicos y filósofos y no tuvo nada que objetar mientras los innovadores no pretendieran poseer una verdad o una certeza que suponía un claro desafio a las 
doctrinas recibidas" (ibídem: 72). La pasividad de los laicos ante el mensaje de estos nuevos "profetas", como son definidos por B. Nelson, es la mejor muestra de que este término no resulta demasiado apropiado para caracterizar a los que se considera como pioneros de la ciencia. Esta constatación no tiene por qué afectar a la tesis que aquél defiende, pero lo cierto es que la revelación profética remite, como bien vio $\mathrm{M}$. Weber, a una visión unitaria de la vida que inculca un determinado habitus que afecta a los laicos. Y ello ya sea porque el carisma se impone como una cualidad que irrumpe extraordinariamente ("es específico de los profetas que no reciben su misión por encargo de los hombres, sino que la usurpan") (Weber, 1944: 359) o porque el habitus de la profecía está objetivamente acorde con el habitus de sus destinatarios (Bourdieu, 2000: 58).

Si en la tradición católica el papel de mediadores entre los discursos de la religión y la ciencia lo cumplieron los llamados profetas católicos de la ciencia, en la tradición protestante ese cometido lo desempeñaron los jerarcas puritanos. $\mathrm{Al}$ igual que aquéllos, estos mediadores administraban dos principios que en un momento histórico coincidieron y que hasta entonces habían estado enfrentados. En efecto, anteriormente se señalaba cómo el criterio utilitario iba desplazando a la glorificación de Dios como motivación de la práctica científica. En el Christian Directory se evidencia cómo R. Baxter actúa como mediador entre estas dos lógicas religiosa y utilitaria. Teniendo como objetivo básico un ethos religioso, sin embargo, se empieza a supeditar la contemplación religiosa al utilitarismo: "deben entregarse menos a la contemplación y preferir el mayor bien". Capítulo aparte merecen los grandes reformadores. Como señala R.K. Merton, Lutero y Calvino no eran entusiastas de la ciencia. Lutero era hostil con ella, ya que consideraba que la justificación por la fe era el único camino válido para la salvación. El caso de Calvino era mucho más contradictorio: "Calvino fue ambivalente, concedía alguna virtud al intelecto práctico, pero mucho menos que la debida al conocimiento revelado" (Merton, 1964: 595). Posteriormente, la ética religiosa del movimiento calvinista-puritano fue la que promovió un estado de espíritu y una orientación axiológica que invitaban al cultivo de la ciencia (ibídem: 595). La acción de estos mediadores tuvo unos efectos inintencionados e indeseados, ya que contribuyeron a cimentar un discurso científico que poco a poco iba dejando de necesitar de soporte religioso alguno. R.K. Merton resaltaba esta tesis como una de sus principales aportaciones: "uno de los resultados básicos de este estudio es el hecho de que la influencia más significativa del puritanismo sobre la ciencia fue en gran medida involuntaria en los jefes puritanos. Que el mismo Calvino execrase la ciencia no hace más que acentuar la paradoja de que él diese origen a un vigoroso movimiento que promovió el interés por este campo" (Merton: 1984: 88).

Como consecuencia no prevista los mediadores dieron lugar a un mundo extraño a sus motivaciones originarias, un mundo en el que la ciencia ya no necesitaba de la religión: "La posibilidad de que la ciencia, como medio de 
RIS

REVISTA INTERNACIONAL DE SOCIOLOGIA

No 31 , Enero - Abril, 2002

JOSE A. SANTIAGO GARCÍA

lograr un fin religioso, posteriormente se apartase de tales soportes religiosos y, en cierta medida, tendiera a delimitar el ámbito del control teológico al parecer no se percibía" (Merton, 1984: 108). Se puede observar aquí cómo R.K. Merton también aplicaba el principio weberiano de la heterogonía de los fines al cambio histórico de la religión a la ciencia. $\mathrm{Al}$ igual que señalaba $\mathrm{M}$. Weber a propósito del capitalismo, también con la ciencia el ascetismo intramundano actuó como el mediador paradójico que "quería hacer el bien y siempre hacía el mal". Con esta fórmula, M. Weber invertía la célebre frase de Mefistófeles en el Fausto de Goethe para proclamar su particular interpretación del principio de la heterogonía de los fines ${ }^{7}$.

\section{CONCLUSIONES}

Impulsada por la religión, la ciencia se diferencia y emancipa, desarrollándose en su propia esfera sin necesidad de ningún soporte religioso. Es evidente el paralelismo con la tesis de M. Weber sobre el origen del capitalismo moderno. En las páginas finales de La ética protestante se puede leer que "el capitalismo victorioso descansando como descansa en un fundamento mecánico, ya no necesita, en todo caso, de su sostén (religioso)" (Weber, 1987: 200). Si sustituimos "capitalismo" por "ciencia" veremos la similitud entre ambos procesos. La ciencia iba tomando cada vez más terreno a los presupuestos sagrados sobre los que se basaba y que contribuyeron a su desarrollo: "los conflictos aparentes entre la teología y la ciencia que surgieron cuando los hallazgos científicos parecían refutar diversas afirmaciones de los teólogos ortodoxos se produjeron más tarde, con cada extensión de la indagación científica, a ámbitos que hasta entonces eran considerados como sagrados" (Merton, 1984: 108). Como señalaba M. Weber, el desarrollo de la ciencia completaba el proceso de desencantamiento del mundo, originado por las

\footnotetext{
${ }^{7}$ En efecto, como especialmente destacó W. Stark (1971: 205-207), M. Weber llevó a cabo la inversión del modelo liberal e ilustrado de la heterogonía de los fines. La versión optimista de las consecuencias no previstas de la acción, presente en B. Mandeville con su fórmula "vicios privados, virtudes publicas", en A. Smith con su "mano invisible" y en I. Kant con su principio de la "insociable sociabilidad", se torna con M. Weber en una versión pesimista y trágica que se resume en la inversión de la famosa frase de Mefistófeles. Aquel pasaje deja ver la influencia de Goethe en la obra de M. Weber, de la que nos ha dado cuenta J.M. González (1992).
} 
profecías antiguas e impulsado por el gran propulsor de la ciencia, el ascetismo intramundano. En La ciencia como vocación, M. Weber mostraba cómo el conocimiento científico desencanta el mundo negando la pretensión de que tenga sentido: “¿quién cree todavía hoy que los conocimientos astronómicos, biológicos, físicos o químicos pueden enseñarnos algo sobre el sentido del mundo [...]? [...] Si tales conocimientos tienen algún efecto es más bien el de secar de raíz la fe en que existe algo que pueda llamarse 'sentido' del mundo" (Weber, 1987: 205-206).

La teología fue perdiendo terreno y sus intereses quedaron hipotecados a los de la ciencia. Como señaló S. Toulmin, la organización social del trabajo científico culminó todo este proceso: "Con la fragmentación profesional del trabajo científico que empezó sobre 1820 o 1830, comenzó la tensión. Todas las cuestiones que surgieron dentro de determinadas disciplinas científicas tenían sus correspondientes grupos de personas cuya labor era tratar de ellas; por el contrario, la integración de los resultados científicos en una cosmología general, transdisciplinar, y la interpretación teológica de la estructura resultante no constituían la tarea profesional de nadie. A partir de 1860, surgieron nuevas generaciones de científicos que ya ni sabían ni les importaba que las llamadas "leyes de la naturaleza" habían recibido su nombre originalmente por ser "leyes decretadas por Dios Creador", y que no se sentían obligados por los términos de la alianza entre Ciencia y Teología implícita en la 'filosofía natural' de Newton" (Toulmin, 1981:23). La división del trabajo científico rompió con la coordinación e integración que proporcionaba la teología natural. La fragmentación disciplinar de la ciencia hacía innecesarias las funciones de integración y coherencia de la teología natural. El proceso que se originaba con el impulso que la religión dio a la ciencia tuvo como consecuencia no prevista la expulsión de la teología natural de la indagación científica ${ }^{8}$.

\footnotetext{
${ }^{8}$ Ahora bien, la ciencia se liberaba de la religión al mismo tiempo que se sacralizaba ella misma a partir de unos presupuestos que escondían viejos postulados teológicos, como el que atendía al carácter absoluto de la verdad. Como señala M. Beltrán: "el desencantamiento del mundo llevado a cabo por la ciencia implicó paradójicamente un proceso de sacralización de la propia ciencia" (Beltrán: 1999, 302). El propio M. Beltrán da cuenta, en el artículo citado, del proceso de secularización de la ciencia en tanto que pérdida de su carácter sagrado.
} 
RIS

REVISTA INTERNACIONAL DE SOCIOLOCIA

№ 31 , Enero - Abril, 2002

JOSE A. SANTIAGO GARCíA

\section{REFERENCIAS BIBLIOGRÁFICAS}

BECKER, C. (1932), "The Laws of Nature and Nature's God", The Heavenly City of the Eightenth-Century Philosophers, New Haven, Yale University Press.

BELTRÁN, M. (1999), "Sobre la confianza en una ciencia secularizada", en R. Ramos y F. García Selgas (coords.), Globalización, riesgo, reflexividad, Madrid, CIS.

BOURDIEU, P. (2000), "Una interpretación de la teoría de la religión según Max Weber", en P. Bourdieu, Intelectuales, política y poder, Buenos Aires, Eudeba, pp. 43-62.

CASANOVA, J. (2000), Religiones públicas en el mundo moderno, Madrid, PPC.

COHEN, I.B. (1990), "Introduction: The Impact of Merton Thesis", Puritanism and the Rise of Modern Science: the Merton Thesis, New Brunswick, Rutgers University Press.

DOBBELAERE, K. (1981), "Secularization: a Multidimensional Concept", Current Sociology, vol. $29, n^{\circ} 2$, pp. $2-213$.

(1999), "Towards an Integrated Perspective of the Processes Related to the Descriptive Concept of Secularization”, Sociology of Religion, vol. 60, n 3, pp. 229-247.

DURKHEIM, E. (1982), Las formas elementales de la vida religiosa, Madrid, Akal.

GÓMEZ ARBOLEYA, E. (1957), Historia de la estructura y el pensamiento social, Madrid, Instituto de Estudios Políticos.

GONZÁLEZ, J.M. (1992), Las huellas de Fausto, Madrid, Tecnos.

IRANZO, J.M. (1992), El giro sociológico en la teoría de la ciencia, ¿una revolución en marcha?, Tesis doctoral, Madrid, U.C.M.

IRANZO, J.M. y J.R. BLANCO (1999), Sociología del conocimiento cientifico, Madrid, CIS.

JAMESON, F. (1974), “The Vanishing Mediator: Narrative Structure in Max Weber”, New German Critique, vol.1, pp. 53-89.

LAMO DE ESPINOSA, E., J.Ma . GÓNZALEZ GARCÍA y C. TORRES (1994), La sociología del conocimiento y de la ciencia, Madrid, Alianza.

MEDINA, E. (1995), "La polémica internalismo/externalismo en la historia y la sociología de la ciencia" en J.M. Iranzo, et al. (coord.), Sociologia de la ciencia y la tecnología, Madrid, CSIC. pp. 65-81.

MERTON, R.K. (1964), "Puritanismo, pietismo y ciencia", Teoría y estructuras sociales, México, FCE, pp. 565-595.

(1980), "Las consecuencias imprevistas de la acción social", Ambivalencia sociológica y otros ensayos, pp. 173-185. 
(1984), Ciencia, tecnología y sociedad en la Inglaterra del XVII, Madrid, Alianza.

NEEDHAM, J. (1977), "La ley humana y las leyes de la naturaleza”, La gran titulación: ciencia y sociedad en Oriente y Occidente, Madrid, Alianza, pp. 299-328.

NELSON, B. (1976), “Los comienzos de la moderna revolución científica y filosófica: ficcionalismo, probabilismo, fideísmo y 'profetismo' católico”, en N. R. Hanson. B. Nelson y P.K. Feyerabend (coords.), Filosofia de la ciencia y religión, Salamanca, Sígueme, pp. 53-95.

QUINTANILLA, M.A. (1976), “Prólogo" en N. R. Hanson, B. Nelson y P. K. Feyerabend (coords.), Filosofia de la ciencia y religión, Salamanca, Sígueme, pp. 9-17.

RAMOS, R. (2001), "La ciudad en la historia: comparación, análisis y narración en la sociología histórica de Max Weber", Política y Sociedad, no 38, pp. 45-67.

SCHRÖDINGER, E. (1975), ¿Qué es una ley de la naturaleza?, México, F.C.E.

STARK, W. (1971), "Max Weber y la heterogonía de los fines”, en T. Parsons et al. (eds.), Presencia de Max Weber, Buenos Aires, Nueva Visión, pp. 191-208.

TOULMIN, S. (1981), "El futuro de la cosmología. ¿Pueden volver a reunirse la Ciencia y la Teología Natural?", Teorema, Vol. 11.

WEBER, M. (1944), Economía y Sociedad, México, FCE.

(1987), Ensayos sobre Sociología de la Religión, vol. I, Madrid, Taurus.

(1988), El político y el cientifico, Madrid, Alianza. 